\title{
COMUNICAÇÃO
}

\section{SELEÇÃO DE LINHAGENS DE MELANCIA RESISTENTES AO Watermelon mosaic virus E AO Papaya ringspot virus ${ }^{1}$}

\author{
Selection of resistant watermelon lines to Watermelon mosaic virus and Papaya ringspot virus
}

\author{
José Evando Aguiar Beserra Júnior², Antonia dos Reis Figueira², Wilson Roberto Maluf ${ }^{3}$
}

\begin{abstract}
RESUMO
Foram avaliadas 20 linhagens de melancia, provenientes do cruzamento da cultivar comercial suscetível Crimson Sweet e da introdução PI 595201 resistente ao Watermelon mosaic virus (WMV) e Papaya ringspot virus (PRSV-W). As linhagens, e os parentais foram inoculados com o WMV ou com o PRSV-W em casa-de-vegetação distintas. Aos 35 e 49 dias após a primeira inoculação (DAI), as plantas foram avaliadas por meio de uma escala de notas, em que 1 (ausência de sintomas) a 5 (intenso mosaico e deformações foliares). Pelos resultados infere-se que, aos 35 DAI, as linhagens 1, 2 e 20 apresentaram resistência tanto para o WMV como para o PRSV-W, com médias de 1,95, 1,80 e 2,25 para o WMV, e de 2,50, 2,30 e 2,50 para o PRSV-W, respectivamente. As linhagens 5, 7 e 13 foram resistentes somente ao WMV e as plantas das linhagens 3, 10 e 18 para o PRSV-W. A reação das linhagens permaneceu em geral pouco alterada aos 49 DAI. A existência de linhagens resistentes somente ao WMV e somente ao PRSV-W, ao lado de linhagens resistentes a ambos os vírus, é indicativo de que as resistências ao WMV e ao PRSV-W não são controladas pelos mesmos genes.
\end{abstract}

Termos para indexação: Controle genético, Cucurbitaceae, Potyvirus.

\begin{abstract}
Twenty advanced watermelon breeding lines, derived from the cross between cv. Crimson Sweet (susceptible) and PI 595201 (resistant to WMV and PRSV-W), were screened for resistance to both potyviruses. The twenty lines, among with Crimson Sweet and PI 595201, were inoculated with either WMV or PRSV-W, in two different greenhouse trials. Plants were evaluated for symptoms 35 and 49 days after the first inoculation (DAI), using a scale from 1 (no symptoms) to 5 (severe mosaic and foliar distortion). Evaluations at 35 DAI indicated that lines 1, 2 and 20 had good levels of resistance to both WMV and PRSV-W, with ratings of 1,95, 1,80 and 2,25 for WMV, and of 2,50, 2,30 and 2,50 for PRSV-W, respectively. Lines 5, 7 and 13 were resistant to WMV only, whereas lines 3,10 and 18 were resistant to PRSV-W only. The reaction of the lines 49 DAI remained essentially unchanged. The existence of lines with resistance to WMV only and to PRSV-W only, along with lines with resistance to both viruses, indicates that resistance to WMV and PRSV-W are under control of different genes.
\end{abstract}

Index terms: Cucurbitaceae, genetic control, Potyvirus.

(Recebido em 15 de julho de 2005 e aprovado em 24 de maio de 2006)

A melancia encontra-se entre as cinco hortaliças mais cultivadas no Brasil, com as Regiões Nordeste e Sul sendo as principais produtoras. Em 2002, a Região Sul foi responsável por $35 \%$ da produção nacional, seguida da Região Nordeste com 27\% (AGRIANUAL, 2005).

Apesar das dificuldades, os programas de melhoramento têm produzido plantas com características desejáveis, como pode ser observado na cultura da melancia, na qual a alta produtividade, resistência ao transporte, resistência à antracnose e fusariose podem ser encontradas na cultivar Crimson Sweet, uma das mais plantadas no Brasil (ALVARENGA \& RESENDE, 2002). Entretanto, atualmente não existem variedades de melancia resistentes a vírus sendo comercializadas, apesar da existência de fontes de melancia resistentes a potyvírus (OLIVEIRA et al., 2002; SILVEIRA et al., 2005).

O Watermelon mosaic virus (vírus do mosaico da melancia, WMV), e o Papaya ringspot virus - watermelon strain (vírus da mancha anelar do mamoeiro - estirpe melancia, PRSV-W), ambos pertencentes à família Potyviridae, gênero Potyvirus, estão entre os principais vírus responsáveis pelos prejuízos em cultivos de cucurbitáceas no País (ZAMBOLIM \& DUSI, 1995).

O WMV e o PRSV-W induzem sintomas de mosqueado, mosaico, clorose, bolhas, necrose, deformação foliar e de frutos e, às vezes, ocorrem infecções latentes.

\footnotetext{
${ }^{1}$ Extraído da Dissertação de Mestrado do primeiro autor.

Departamento de Fitopatologia/DFP - Universidade Federal de Lavras/UFLA - Cx. P. 3037 - $37200-000$ - Lavras, MG - evandojr@vicosa.ufv.br,

antonia@ufla.br
${ }^{3}$ Departamento de Agricultura/DAG - Universidade Federal de Lavras/UFLA - Cx. P. 3037 - 37200-000 - Lavras, MG - wrmaluf@ufla.br
} 
Os vírus podem reduzir a qualidade e a quantidade dos frutos (RAMOS et al., 2003). De forma geral, as folhas desenvolvem amarelecimento entre as nervuras e, em seguida, tornam-se deformadas e o tecido próximo à nervura central fica enrugado. Nas folhas mais novas, aparece mosaico mais severo com bolhas, o que as tornam deformadas. A planta apresenta redução de tamanho e o fruto pode, algumas vezes, ficar verrugoso e com coloração mais escura (GRAY et al., 1988).

Os vírus são transmitidos de maneira nãopersistente por mais de 38 espécies de afídeos (FAUQUET et al., 2005). Portanto, o controle químico dos insetos vetores não apresenta resultado satisfatório no combate à doença. Conseqüentemente, a forma de controle mais eficiente consiste em utilizar cultivares resistentes.

O programa de melhoramento genético da HortiAgro Sementes Ltda, localizada no município de Ijaci - MG, obteve linhagens a partir de cruzamentos entre Crimson Sweet x PI 595201, seguidos de retrocruzamentos para Crimson Sweet. As linhagens foram selecionadas para características comerciais e assemelham-se a cultivar comercial Crimson Sweet. A introdução PI 595201 foi disponibilizada pelo United States Department of Agriculture (USDA) como germoplasma resistente ao WMV (CUCURBIT GENETICS COOPERATIVE, 1996), porém sem características agronômicas desejáveis. Entretanto, durante o processo de obtenção das linhagens, apenas foram utilizados isolados de PRSV-W para inoculação e seleção de plantas resistentes entre e dentro de famílias. Não se utilizou nenhum tipo de seleção visando especificamente a resistência ao WMV.

Cultivares portadoras de resistência a esses dois potyvírus seriam valiosas, por serem vírus altamente disseminados em cultivos de cucurbitáceas em grande parte do território nacional (MOURA et al., 2001; YUKI et al., 2000) e, especialmente, pela freqüente ocorrência de infecções mistas que são observadas em condições naturais (DAVIS \& MIZUKI, 1987). Nesse tipo de infecção podem ocorrer reações sinérgicas, ocasionando elevação ou redução na concentração de vírus e, conseqüentemente, alteração na sintomatologia (OLIVEIRA et al., 2000).

Em busca de cultivares de melancia resistentes ao WMV e ao PRSV-W, o presente trabalho teve como objetivo avaliar 20 linhagens avançadas provenientes do cruzamento da cultivar comercial suscetível Crimson Sweet e da introdução resistente PI 595201.

\section{Isolados virais e procedimento de inoculação}

Para evitar a disseminação dos isolados virais na região, o estudo foi totalmente realizado em casa-devegetação, nas dependências do Departamento de Fitopatologia da Universidade Federal de Lavras, Setor de Virologia Vegetal, durante o segundo semestre de 2003.

Os inóculos do WMV e PRSV-W foram mantidos dessecados em freezer a $-20^{\circ} \mathrm{C}$. Posteriormente, foram multiplicados separadamente em plantas de Cucurbita pepo, cv. Caserta, para serem utilizados na inoculação mecânica das plantas a serem avaliadas.

A resistência ao WMV ou ao PRSV-W foi avaliada em 20 linhagens de melancia, sendo estas produtos de cruzamentos entre as cultivares Crimson Sweet (suscetível) x PI 595201 (resistente), seguidos de retrocruzamentos para Crimson Sweet. A fim de evitar infecção mista, os experimentos foram conduzidos em casas-de-vegetação distintas. Além das linhagens, também foram testadas os parentais Crimson Sweet e PI 595201. O delineamento experimental utilizado foi de blocos casualizados, consistindo a parcela de 4 plantas com 5 repetições.

Os isolados virais usados nas inoculações foram obtidos a partir de folhas jovens de Cucurbita pepo cv. Caserta, previamente inoculadas com WMV ou com o PRSV-W, apresentando sintomas de mosaico severo. As folhas foram trituradas com auxílio de $\mathrm{N}$ líquido com posterior adição de tampão fosfato de potássio $0,01 \mathrm{M}, \mathrm{pH}$ 7,0 e sulfito de sódio na mesma molaridade, na proporção de 1 grama de tecido foliar para $5 \mathrm{~mL}$ de tampão (p/v). A inoculação foi realizada por fricção da suspensão viral sobre as folhas cotiledonares, previamente polvilhadas com o abrasivo carborundum 400 mesh.

Foram realizadas quatro inoculações para cada vírus, para evitar a ocorrência de escape, sendo a primeira no estádio de folhas cotiledonares expandidas e, as subseqüentes, em intervalos de 2 dias.

\section{Avaliações}

Foram realizadas duas avaliações, sendo a primeira aos 35 e a segunda aos 49 dias após a primeira inoculação. As plantas foram avaliadas individualmente, pelo mesmo operador, de acordo com a severidade dos sintomas induzidos pelo WMV ou PRSV-W. Foi adotado o sistema de escala de notas na classificação da severidade dos sintomas de acordo com Oliveira et al. (2003):

$1=$ Folhas sem sintomas.

$2=$ Poucas folhas com leve mosaico nos bordos.

3 = Maioria das folhas com mosaico; poucas bolhas. 
4 = Maioria das folhas com mosaico; muitas bolhas e/ou folhas com leves deformações.

5 = Mosaico intenso e folhas com deformações severas.

Constatou-se resistência parcial em algumas das

linhagens testadas. Aos 35 dias após a primeira inoculação, as linhagens 1, 2 e 20 apresentaram resistência para ambos os vírus, com médias de 1,95, 1,80 e 2,25 para o WMV e de 2,50, 2,30 e 2,50 para o PRSV-W (Tabela 1). As linhagens 5, 7 e 13 foram resistentes somente ao WMV e as plantas das linhagens 3, 10 e 18 para o PRSV-W.

Aos 49 dias, as linhagens 1, 2 e 20 permaneceram resistentes a ambos os vírus, com médias de 1,80, 1,70 e 2,20 para o WMV e 2,13, 1,95 e 2,75 para o PRSV-W, respectivamente. As linhagens 5, 7 e 13 continuaram a manifestar resistência apenas ao WMV, bem como as linhagens 3, 10 e 18 para o PRSV-W (Tabela 2). Diante do pequeno número de linhagens testadas, a quantidade de linhagens resistentes pode ser considerada bastante satisfatória.

Como nenhuma das linhagens apresentou média semelhante à da parental resistente, levaram-se em consideração a menor e a maior nota obtida em cada linhagem, bem como o valor da média das notas de todas as plantas da linhagem, a fim de se determinar sua resistência ou suscetibilidade aos vírus. A linhagem, cuja maior nota foi igual ou inferior à menor nota da parental suscetível (Crimson Sweet) foi considerada resistente.

TABELA 1 - Notas atribuídas na avaliação da resistência de 20 linhagens de melancia, feita aos 35 dias após a primeira inoculação com Watermelon mosaic virus ou Papaya ringspot virus-watermelon strain.

\begin{tabular}{|c|c|c|c|c|c|c|}
\hline \multirow[b]{2}{*}{ Parentais } & \multicolumn{3}{|c|}{ Inoculadas com WMV } & \multicolumn{3}{|c|}{ Inoculadas com PRSV-W } \\
\hline & $\begin{array}{c}\text { Menor } \\
\text { Nota }\end{array}$ & Média & $\begin{array}{c}\text { Maior } \\
\text { Nota }\end{array}$ & $\begin{array}{c}\text { Menor } \\
\text { Nota }\end{array}$ & Média & $\begin{array}{r}\text { Maior } \\
\text { Nota }\end{array}$ \\
\hline Crimson Sweet & $3,00^{*}$ & 4,00 & 5,00 & 3,00 & 4,00 & 5,00 \\
\hline PI 595201 & 1,00 & 1,00 & 1,00 & 1,00 & 1,26 & 2,00 \\
\hline Linhagens & & & & & & \\
\hline 1- WMX-001Fpl\# 09-04-03-03 & 1,00 & 1,95 & 3,00 & 1,00 & 2,50 & 3,00 \\
\hline 2- WMX-001Fpl\# 09-04-58-07 & 1,00 & 1,80 & 2,00 & 1,00 & 2,30 & 3,00 \\
\hline 3- WMX-001Fpl\# 12-03-07-04 & 2,00 & 3,05 & 4,00 & 2,00 & 2,55 & 4,00 \\
\hline 4- WMX-001Fpl\# 12-03-07-06 & 2,00 & 3,15 & 4,00 & 2,00 & 2,80 & 3,00 \\
\hline 5- WMX-001Fpl\# 14-02-55-01 & 1,00 & 1,80 & 3,00 & 2,00 & 2,75 & 4,00 \\
\hline 6- WMX-001Fpl\# 14-04-67-06 & 2,00 & 2,75 & 4,00 & 2,00 & 2,85 & 4,00 \\
\hline 7- WMX-001Fpl\# 18-02-09-03 & 2,00 & 2,57 & 3,00 & 2,00 & 3,40 & 4,00 \\
\hline 8- WMX-001Fpl\# 18-02-11-01 & 2,00 & 2,65 & 4,00 & 3,00 & 3,10 & 4,00 \\
\hline 9- WMX-001Fpl\# 18-02-11-03 & 2,00 & 3,05 & 4,00 & 2,00 & 3,20 & 4,00 \\
\hline 10- WMX-001Fpl\# 24-01-56-01 & 1,00 & 2,95 & 4,00 & 1,00 & 2,40 & 3,00 \\
\hline 11- WMX-001Fpl\# 03-03-14-05 & 2,00 & 2,80 & 3,00 & 2,00 & 3,15 & 4,00 \\
\hline 12- WMX-001Fpl\# 03-03-14-08 & 3,00 & 3,10 & 4,00 & 2,00 & 2,95 & 4,00 \\
\hline 13- WMX-001Fpl\# 03-03-53-01 & 1,00 & 2,55 & 3,00 & 2,00 & 3,10 & 4,00 \\
\hline 14- WMX-001Fpl\# 06-03-02-04 & 3,00 & 3,15 & 4,00 & 2,00 & 3,30 & 4,00 \\
\hline 15- WMX-001Fpl\# 06-01-25-03 & 2,00 & 2,85 & 3,00 & 2,00 & 3,60 & 5,00 \\
\hline 16- WMX-001Fpl\# 06-03-42-06 & 1,00 & 2,70 & 4,00 & 2,00 & 3,40 & 5,00 \\
\hline 17- WMX-001Fpl\# 06-04-01-08 & 2,00 & 3,10 & 4,00 & 2,00 & 4,45 & 5,00 \\
\hline 18- WMX-001Fpl\# 07-01-59-04 & 2,00 & 2,94 & 4,00 & 1,00 & 2,45 & 3,00 \\
\hline 19- WMX-001Fpl\# 19-02-16-06 & 2,00 & 2,75 & 4,00 & 2,00 & 3,05 & 4,00 \\
\hline 20- WMX-001Fpl\# 09-04-03-01 & 2,00 & 2,25 & 3,00 & 1,00 & 2,50 & 4,00 \\
\hline
\end{tabular}

1- Folhas sem sintomas, 2- Poucas folhas com leve mosaico nos bordos, 3- Maioria das folhas com mosaico; poucas bolhas, 4- Maioria das folhas com mosaico; muitas bolhas e/ou folhas com leves deformações, 5- Mosaico intenso e folhas com deformações severas. 
TABELA 2 - Notas atribuídas na avaliação da resistência de 20 linhagens de melancia, feita aos 49 dias após a primeira inoculação com Watermelon mosaic virus ou Papaya ringspot virus-watermelon strain.

\begin{tabular}{|c|c|c|c|c|c|c|}
\hline \multirow[b]{2}{*}{ Parentais } & \multicolumn{3}{|c|}{ Inoculadas com WMV } & \multicolumn{3}{|c|}{ Inoculadas com PRSV-W } \\
\hline & $\begin{array}{c}\text { Menor } \\
\text { Nota }\end{array}$ & Média & $\begin{array}{c}\text { Maior } \\
\text { Nota }\end{array}$ & $\begin{array}{c}\text { Menor } \\
\text { Nota }\end{array}$ & Média & $\begin{array}{c}\text { Maior } \\
\text { Nota }\end{array}$ \\
\hline Crimson Sweet & $3,00 *$ & 4,00 & 5,00 & 3,00 & 4,00 & 5,00 \\
\hline PI 595201 & 1,00 & 1,00 & 1,00 & 1,00 & 1,26 & 2,00 \\
\hline Linhagens & & & & & & \\
\hline 1- WMX-001Fpl\# 09-04-03-03 & 1,00 & 1,80 & 2,00 & 1,00 & 2,13 & 3,00 \\
\hline 2- WMX-001Fpl\# 09-04-58-07 & 1,00 & 1,70 & 2,00 & 1,00 & 1,95 & 3,00 \\
\hline 3- WMX-001Fpl\# 12-03-07-04 & 2,00 & 2,85 & 3,00 & 2,00 & 2,55 & 3,00 \\
\hline 4- WMX-001Fpl\# 12-03-07-06 & 2,00 & 2,95 & 4,00 & 3,00 & 3,10 & 4,00 \\
\hline 5- WMX-001Fpl\# 14-02-55-01 & 1,00 & 2,00 & 3,00 & 2,00 & 3,00 & 4,00 \\
\hline 6- WMX-001Fpl\# 14-04-67-06 & 2,00 & 2,55 & 3,00 & 2,00 & 2,85 & 4,00 \\
\hline 7- WMX-001Fpl\# 18-02-09-03 & 1,00 & 2,25 & 3,00 & 2,00 & 3,35 & 4,00 \\
\hline 8- WMX-001Fpl\# 18-02-11-01 & 1,00 & 2,45 & 4,00 & 3,00 & 3,05 & 4,00 \\
\hline 9- WMX-001Fpl\# 18-02-11-03 & 2,00 & 2,80 & 4,00 & 2,00 & 3,00 & 4,00 \\
\hline 10- WMX-001Fpl\# 24-01-56-01 & 1,00 & 2,65 & 4,00 & 1,00 & 2,40 & 3,00 \\
\hline 11- WMX-001Fpl\# 03-03-14-05 & 2,00 & 2,50 & 3,00 & 2,00 & 2,85 & 4,00 \\
\hline 12- WMX-001Fpl\# 03-03-14-08 & 2,00 & 2,85 & 4,00 & 2,00 & 2,65 & 4,00 \\
\hline 13- WMX-001Fpl\# 03-03-53-01 & 1,00 & 2,65 & 3,00 & 2,00 & 2,80 & 4,00 \\
\hline 14- WMX-001Fpl\# 06-03-02-04 & 2,00 & 3,05 & 4,00 & 2,00 & 2,80 & 4,00 \\
\hline 15- WMX-001Fpl\# 06-01-25-03 & 3,00 & 3,15 & 4,00 & 2,00 & 3,45 & 5,00 \\
\hline 16- WMX-001Fpl\# 06-03-42-06 & 1,00 & 3,00 & 4,00 & 2,00 & 3,20 & 5,00 \\
\hline 17- WMX-001Fpl\# 06-04-01-08 & 3,00 & 3,45 & 4,00 & 3,00 & 4,25 & 5,00 \\
\hline 18- WMX-001Fpl\# 07-01-59-04 & 2,00 & 2,78 & 4,00 & 2,00 & 2,45 & 3,00 \\
\hline 19- WMX-001Fpl\# 19-02-16-06 & 2,00 & 2,95 & 4,00 & 2,00 & 2,70 & 4,00 \\
\hline 20- WMX-001Fpl\# 09-04-03-01 & 1,00 & 2,20 & 3,00 & 2,00 & 2,75 & 4,00 \\
\hline
\end{tabular}

1- Folhas sem sintomas, 2- Poucas folhas com leve mosaico nos bordos, 3- Maioria das folhas com mosaico; poucas bolhas, 4- Maioria das folhas com mosaico; muitas bolhas e/ou folhas com leves deformações, 5- Mosaico intenso e folhas com deformações severas.

Dada a relação filogenética entre WMV e PRSV-W, ambos potyvírus, poder-se-ia especular sobre a possível relação de alelismo entre os genes que controlam resistência a esses vírus. Contudo, os resultados do presente trabalho não suportam essa hipótese. A existência de linhagens resistentes apenas ao WMV, bem como apenas ao PRSV-W, ao lado de linhagens resistentes a ambos, parece indicar que os genes que controlam resistência ao WMV em PI 595201 não são todos alélicos, quando comparados àqueles que controlam resistência ao PRSV-W.

Para muitas espécies vegetais é comum encontrar o mesmo locus conferindo resistência a diferentes potyvírus, podendo ser essa resistência condicionada por vários genes independentes, por genes correlacionados ou por um único gene (WAI \& GRUMET, 1995). Baseados em infecção mista obtida pela inoculação mecânica de plantas de Cucurbita moschata cv. Menina com os potyvírus Zucchini yellow mosaic virus (vírus do mosaico amarelo da abobrinha - ZYMV) e WMV, Gilbert-Albertini et al. (1993) identificaram um gene dominante denominado Zym, ou talvez dois genes estritamente relacionados, conferindo resistência a ambos os vírus.

Em Phaseolus vulgaris, o alelo dominante I conferiu resistência a 5 potyvírus: Bean common mosaic virus (vírus do mosaico comum do feijoeiro - BCMV), Blackeye cowpea mosaic virus (vírus do mosaico do caupi blackeye - BICMV), Cowpea aphid-borne mosaic virus (vírus do mosaico do caupi - CABMV), Passionfruit woodiness virus (vírus do endurecimento dos frutos do maracujá-PWV) e WMV em temperaturas abaixo de $30^{\circ} \mathrm{C}$ 
(KYLE \& DICKSON, 1988). Estudos da herança da resistência ao Bean yellow mosaic virus (vírus do mosaico amarelo do feijoeiro - BYMV) e ao WMV em Pisum sativum constataram que 32 cultivares possuindo o gene recessivo mo mo para resistência ao BYMV também foram resistentes ao WMV e que outras 32 cultivares possuindo o gene dominante Mo Mo para suscetibilidade ao BYMV foram completamente suscetíveis ao WMV (SCHROEDER \& PROVVIDENTI, 1971).

Dentre as 20 linhagens avaliadas, pelo fato de nenhuma linhagem dita resistente ao WMV ou ao PRSVW ter obtido o mesmo nível de resistência da linhagem parental PI 595201, infere-se que ocorre um controle oligo ou poligênico dessas resistências, conforme encontrado por Azevedo (2001) para o PRSV-W.

\section{AGRADECIMENTOS}

Os autores agradecem ao CNPq (Conselho Nacional de Desenvolvimento Científico e Tecnológico/MCT).

\section{REFERÊNCIAS BIBLIOGRÁFICAS}

AGRIANUAL. Anuário da agricultura brasileira. 10. ed. São Paulo: FNP, 2005. 520 p.

ALVARENGA, M. A. R.; REZENDE, G. M. de. Cultura da melancia. Lavras: UFLA, 2002. 133 p.

AZEVEDO, S. M. Herança da resistência ao vírus da mancha anelar do mamoeiro-estirpe melancia (PRSV-W) em melancia, Citrullus lanatus (Thunb.) Matsu. \& Nakai. 2001. 53 f. Tese (Doutorado em Fitotecnia) - Universidade Federal de Lavras, Lavras, 2001.

CUCURBIT GENETICS COOPERATIVE. Release of Watermelon mosaic virus (WMV) resistant watermelon brindings lines WM-1, WM-2, WM-3 and WM-4. Annual Report, [S.1.], v. 19, p. 95, July 1996.

DAVIS, R. F.; MIZUKI, M. K. Detection of cucurbit viruses in New Jersey. Plant Disease, Saint Paul, v. 71, n. 1, p. 4044, 1987.

FAUQUET, C. M.; MAYO, M. A.; MANILOFF, J.; DESSELBERGER, U.; BALL, L. A. Virus taxonomy: eighth report of the International Committee on Taxonomy of Viruses. Washington: Academic, 2005.

GILBERT-ALBERTINI, F.; LECOQ, H.; PITRAT, M.; NICOLET, J. L. Resistance of Cucurbita moschata to watermelon mosaic virus type 2 and its genetic relation to Zucchini yellow mosaic virus. Euphytica, Dordrecht, v. 69, n. 3, p. 231-237, 1993.

GRAY, S. M.; MOYER, J. W.; KENNEDY, G. G. Resistance in Cucumis melo to Watermelon mosaic virus 2 correlated with reduced virus movement within leaves. Phytophatology, Saint Paul, v. 78, n. 8, p. 1043-1046, 1988.

KYLE, M. M.; DICKSON, M. H. Linkage of hypersensitivity to five potyviruses with the locus for seed color in Phaseolus vulgaris L. Journal of Heredity, Cary, v. 79, n. 4, p. 308-311, 1988.

MOURA, M. C. C. L.; LIMA, J. A. A.; OLIVEIRA, V. B.; GONÇALVES, M. F. B. Identificação sorológica de espécies de vírus que infectam cucurbitáceas e áreas produtoras do Maranhão.Fitopatologia Brasileira, Brasília, v. 26, p. 90-92, 2001.

OLIVEIRA, A. C. B.; MALUF, W. R.; PINTO, J. E. B. P.; AZEVEDO, S. M. Resistance to Papaya ringspot virus in Cucurbita pepo L. introgressed from a interspecific $C$. pepo х C. moschata cross. Euphytica, Wageningen, v. 132, n. 2, p. 211-215, 2003.

OLIVEIRA, V. B.; LIMA, J. A. A.; VALE, C. C.; PAIVA, W. O. Caracterização biológica e sorológica de isolados de potyvirus obtidos de cucurbitáceas no Nordeste brasileiro. Fitopatologia Brasileira, Brasília, v. 25, p. 628-636, 2000.

OLIVEIRA, V. B.; QUEIROZ, M. A.; LIMA, J. A. A. Fontes de resistência em melancia aos principais potyvirus isolados de cucurbitáceas no nordeste brasileiro. Horticultura Brasileira, Brasília, v. 20, p. 589-592, 2002.

RAMOS, N. F.; LIMA, J. A. A.; GONÇALVES, M. F. B. Efeitos da interação de potyvirus em híbridos de meloeiro, variedades de melancia e abobrinha. Fitopatologia Brasileira, Brasília, v. 28, p. 199-203, 2003.

SCHROEDER, W. T.; PROVVIDENTI, R. A common gene for resistance to Bean yellow mosaic virus and Watermelon mosaic virus 2 in Pisum sativum. Phytopathology, Saint Paul, v. 61, n. 7, p. 846-848, 1971.

SILVEIRA, L. M.; QUEIROZ, M. A.; LIMA, J. A. A.; NEGREIROS, M. Z.; RAMOS, N. F.; NASCIMENTO, A. Q. Seleção de acessos a progênies de Citrullus spp. para resistência a três potyvirus. Fitopatologia Brasileira, Brasília, v. 30, p. 394-399, 2005. 
WAI, T.; GRUMET, R. Inheritance of resistance to Watermelon mosaic virus in the cucumber line TMG-1: tissue-specific expression and relationship to Zucchini yellow mosaic virus resistance. Theoretical Applied and Genetics, Berlin, v. 91, n. 4, p. 699-706, 1995.

YUKI, V. A.; REZENDE, J. A. M.; KITAJIMA, E. W. BARROSO, P. V. A.; KUNIYUKI, H.; GROPPO, G. A.;
PAVAN, M. A. Occurrence, distribution, and relative incidence of five viruses infecting cucurbits in the State of São Paulo, Brazil. Plant Disease, Quebec, v. 84, p. 516-520, 2000.

ZAMBOLIM, E. M.; DUSI, A. N. Doenças causadas por vírus em cucurbitáceas. Informe Agropecuário, Belo Horizonte, v. 17, n. 182, p. 60-62, 1995. 